\title{
Determinação de leucometria global, proteínas totais, albumina e globulinas no sangue das veias jugular e mamária de vacas leiteiras com mastite
}

\section{White blood cell count, total blood protein, albumin and globulin in blood from jugular and mammary veins of cows with mastitis}

\author{
Ana Paula Delgado da Costa, ${ }^{*}$ José Renato Junqueira Borges, ${ }^{\star *}$ Cláudio Baptista de Carvalho, ${ }^{* * *}$ \\ Antônio Peixoto Albernaz, ${ }^{* * *}$ Alexandre Pio Viana*****
}

\begin{abstract}
Resumo
A leucometria global e os níveis sangüíneos de proteínas totais, albumina e globulinas foram determinados em vacas leiteiras, pertencentes a propriedades da região Norte do Estado do Rio de Janeiro. Três grupos contendo 15 animais cada, portadoras de mastite clínica (grupo 1), de mastite subclínica (grupo 2) e clinicamente sadias (grupo 3) foram utilizados nas colheitas de sangue, sendo estas realizadas nas veias jugular e mamária para verificar a influência do local de colheita sobre os parâmetros hematológicos supracitados. De acordo com a análise estatística, não houve diferença significativa $(p>0,05)$ entre os diferentes locais de colheita, mas houve diferença significativa $(p<0,05)$ entre os grupos. Os níveis de proteínas totais e globulinas foram mais elevados no grupo 1 (8,06 g/dL; 5,19 g/dL) sendo seguido dos do grupo 2 (7,54 g/dL; 4,42 g/dL) e dos do grupo 3 (6,57 g/dL; 3,77 g/dL), respectivamente. Na determinação da albumina sérica, o grupo 2 apresentou média de 3,13 g/dL, não havendo diferença significativa entre os grupos 1 e 3 (2,87 g/dL; 2,86 g/dL). Na determinação da leucometria global, também houve diferença significativa entres os grupos, sendo o grupo $2\left(13,29 \times 10^{3} / \mu \mathrm{L}\right)$ maior do que o grupo $1\left(12,83 \times 10^{3} / \mu \mathrm{L}\right)$ e do que o grupo $3\left(11,69 \times 10^{3} / \mu \mathrm{L}\right)$. Não houve influência do local de colheita (veia jugular $x$ veia mamária) sobre os níveis sangüíneos de proteínas totais, globulinas, albumina e leucócitos, não havendo, com isso, restrição ao uso de sangue colhido da veia mamária para dosagem destes parâmetros.
\end{abstract}

Palavras-chave: Leucometria, mastite, bovino, local de colheita de sangue, bioquímica.

\begin{abstract}
White blood cell count, total blood protein, globulin and albumin were determined in dairy cattle from North Region of Rio de Janeiro State, Brazil. Forty five cows in lactation were used. They were divided into three groups, cows with clinical mastitis (group 1), with subclinical mastitis (group 2) and clinically healthy (group 3). Blood was collected from jugular and mammary veins in order to determine the sample site influencing the hematological parameters. According to the statistical analysis, significant difference was observed among the tested groups but no difference was observed between the collecting sites (jugular and mammary veins). Total protein and globulin levels were higher in group 1 (8.06 g/dL; $5.19 \mathrm{~g} / \mathrm{dL}$ ), followed by group 2 (7.54 g/dL; $4.42 \mathrm{~g} / \mathrm{dL})$ and group 3 (6.57 g/dL; $3.77 \mathrm{~g} / \mathrm{dL})$. Albumin levels were higher in group 2 (3.13 g/dL) than groups 1 and 3 (2.87 g/dL; $2.86 \mathrm{~g} / \mathrm{dL}$, respectively). In relation to white blood cell count, group $2\left(13.29 \times 10^{3} / \mu \mathrm{L}\right)$ showed higher values, followed by group $1\left(12.83 \times 10^{3} / \mu \mathrm{L}\right)$ and group $3\left(11.69 \times 10^{3} / \mu \mathrm{L}\right)$. Ours findings suggest that, the collecting sites (jugular and mammary veins) didn't influence the evaluation of white blood cell count, total blood protein, globulin and albumin.
\end{abstract}

Keywords: white blood cell count, mastitis, cow, collecting blood sites, biochemistry.

\section{Introdução}

A mastite é uma enfermidade que acomete principalmente 0 gado leiteiro acarretando perdas econômicas. Calcula-se que aproximadamente 17 a $20 \%$ da população mundial de vacas leiteiras em um dado momento tenham mastite. Estimativas feitas em vários países calculam perdas de 10 a $15 \%$ da produção (Du Preez e Giesecke, 1994).

\footnotetext{
"Mestranda em Sanidade Animal LSA/CCTA/UENF- Universidade Estadual do Norte Fluminense Darcy Ribeiro, Campos dos Goytacazes, RJ delcosta@uenf.br

"* Professor da Faculdade de Agronomia e Medicina Veterinária da UnB (Cedido pela UFF)

${ }^{* * *}$ Professor do Laboratório de Sanidade Animal, CCTA/UENF

.... Doutorando em Sanidade Animal, LSA/CCTA/UENF

***** Doutorando em Produção Vegetal, LMGV/CCTA/UENF
} 
A determinação do tipo da mastite (clínica ou subclínica) é importante para a definição dos grupos de animais. A mastite clínica caracteriza-se por alterações visíveis da glândula e/ou do leite. Esta pode ser aguda, apresentando sintomatologia evidente de processo inflamatório (edema, rubor, dor e calor) com ou sem alterações das características do leite; ou crônica, observando-se fibrosamento, ausência dos sinais de processo inflamatório e alterações no leite. A mastite subclínica não possui sintomatologia tão evidente, sendo caracterizada pela diminuição da produção de leite e não apresentando sinais clínicos no animal (Costa, 1998).

A colheita de sangue, na vaca, para análise pode ser obtida principalmente através da punção das veias jugular, mamária e coccígea, segundo Mackelar (1970), Doxey (1971), Medway et al. (1973) e Kelly (1976).

A veia jugular é a mais utilizada, mas apresenta níveis sangüíneos de fósforo inorgânico $(\mathrm{Pi})$ mais baixos devido à drenagem das glândulas salivares. A veia coccígea é o local mais representativo, porque seus componentes não são modificados pela passagem por órgãos secretórios; entretanto, é o local mais sujo e no qual a vaca sofre mais estresse. A veia mamária é fácil de ser utilizada, mas a composição é a mais variada, devido à drenagem da glândula mamária (Payne e PAYNE, 1987). Blowey (1992), Carlson (1996) e Borges et al. (1997) não recomendam o uso da veia mamária, especialmente para a dosagem de glicose.

Parker e Blowey (1974) afirmam que a composição do sangue venoso depende em parte da fisiologia do tecido que a veia drena. Baseado nisso, e no fato de que na prática há um incremento da utilização das veias coccígea e mamária para colheita de sangue para dosagens bioquímicas, considerouse importante estabelecer se nas nossas condições há grande variação nos níveis sangüíneos de proteínas totais, albumina e globulinas conforme o local da colheita.

Esse trabalho teve como objetivo determinar a influência do local de colheita sangüínea (veia jugular $x$ veia mamária) sobre os parâmetros hematológicos associando-se, ainda, o exame clínico do animal para determinar o tipo de mastite (clínica ou subclínica).

\section{Materiais e métodos}

As amostras sangüíneas foram colhidas de 45 vacas leiteiras pertencentes a sete propriedades distintas da região Norte do Estado do Rio de Janeiro. As colheitas foram realizadas em três grupos de 15 animais (portadoras de mastite clínica, de mastite subclínica e clinicamente sadias), nas veias jugular e mamária.

Os animais escolhidos foram submetidos ao exame físico, segundo Marek e Moksy (1995). O exame físico das vacas foi direcionado às doenças de úbere de maior ocorrência.

Em seguida, foi realizado o CMT (do inglês: California Mastitis Test), um teste qualitativo que determina a variação na concentração de células somáticas no leite, para verificar se a vaca era portadora de mastite subclínica (Radostitis et al., 1994). Então, procedeu-se à colheita de sangue da veia jugular, utilizando-se dois tubos de hemólise: um tubo contendo EDTA (anticoagulante), na proporção de uma gota de anticoagulante para $5 \mathrm{~mL}$, de sangue e um outro tubo sem anticoagulante, no qual foram colhidos $10 \mathrm{~mL}$ de sangue para posterior extração do soro sangüíneo. O mesmo procedimento foi utilizado para a colheita de sangue da veia mamária.

Nas colheitas de sangue foram utilizadas seringas de $10 \mathrm{~mL}$ e agulhas $40 \times 12 \mathrm{~mm}$ para as veias jugular e mamária. Os métodos de colheita para as duas veias foram os descritos por Medway (1973).

O sangue seqüestrenizado (com EDTA) foi utilizado para a determinação da leucometria global. O sangue colhido sem anticoagulante foi submetido à extração de soro para a dosagem de proteínas totais e albuminas.

A determinação da leucometria global foi realizada pelo método hemocitométrico, utilizando câmara de Neubauer, pipeta de Thoma para glóbulos brancos e líquido de Turk. Já a determinação dos níveis de proteínas totais e albumina foi feita por meio de espectrofotometria (Microlab 200 - Merck), utilizando-se kits ANALISA Diagnótica Ltda.

Os níveis sangüíneos de globulina foram determinados pela subtração dos níveis sangüíneos de albumina dos de proteínas totais.

Os resultados foram analisados estatisticamente através do programa computacional GENES (Cruz, 2001), sendo utilizado o teste $F(p<0,05)$ e, quando necessário, procedeu-se ao teste de Tukey $(p<0.05)$.

\section{Resultados e discussão}

De acordo com o teste $\mathrm{F}$ a $5 \%$ de probabilidade, não houve diferença significativa entre os diferentes locais de colheita, veias jugular e mamária, em nenhuma das determinações (leucometria global, proteínas totais, albumina e globulina) e nem nos diferentes grupos (vacas sadias, mastite clínica e subclínica), como pode ser observado na Tabela 1. Borges et al. (1997) também não observaram diferença entre os níveis de proteínas totais, albumina e globulina no sangue colhido das veias jugular e mamária.

Segundo Lopes et al. (1996), os níveis sangüíneos normais de proteínas totais variam de 6,74 a 7,46 g/dL; já Kaneko et al. (1997), consideram concentrações entre 5,7 e 8,1 g/dL. No presente trabalho, as vacas consideradas clinicamente sadias apresentaram um valor médio de $6,63 \mathrm{~g} / \mathrm{dL}$ de proteínas totais, enquanto as portadoras de mastite subclínica e clínica apresentaram um aumento de $14,76 \%$ e $22,67 \%$, respectivamente (Tabela 2).

A média dos valores sangüíneos de albumina determinada nas vacas clinicamente sadias foi de $2,86 \mathrm{~g} / \mathrm{dL}$ sendo observado um aumento de $9,44 \%$ e $0,34 \%$ em vacas com mastite subclínica e clínica, respectivamente (Tabela 2). Kaneko et al. (1997) determinaram que estes níveis variam de 2,3 a 4,0 g/ $\mathrm{dL}$, enquanto Lopes et al. (1996) consideraram os valores entre 3,03 e 3,55 g/dL. Whitaker (2000), estudando vacas em lactação, observou níveis maiores do que $3,0 \mathrm{~g} / \mathrm{dL}$. 
Tabela 1: Comparação da utilização de diferentes locais de colheita de sangue (veias jugular e mamária) em 45 vacas leiteiras na região Norte do Estado do Rio de Janeiro

\begin{tabular}{|c|c|c|c|c|c|c|c|c|}
\hline & \multicolumn{2}{|c|}{$\begin{array}{l}\text { Proteínas } \\
\text { totais } \\
(\mathrm{g} / \mathrm{dL})\end{array}$} & \multicolumn{2}{|c|}{$\begin{array}{l}\text { Albumina } \\
(\mathrm{g} / \mathrm{dL})\end{array}$} & \multicolumn{2}{|c|}{$\begin{array}{c}\text { Globulinas } \\
(\mathrm{g} / \mathrm{dL})\end{array}$} & \multicolumn{2}{|c|}{$\begin{array}{c}\text { Leucometria } \\
\text { Global } \\
\left(x 10^{3} / \mu \mathrm{L}\right) \\
\end{array}$} \\
\hline & $\mathrm{VJ}^{1}$ & $\mathrm{VM}^{2}$ & VJ & VM & VJ & VM & VJ & VM \\
\hline $\begin{array}{l}\text { Vacas } \\
\text { sadias }\end{array}$ & $6,58 \mathrm{a}$ & $6,56 \mathrm{a}$ & $2,90 \mathrm{a}$ & $2,82 \mathrm{a}$ & $3,42 \mathrm{a}$ & $3,87 \mathrm{a}$ & $11,75 \mathrm{a}$ & $12,48 \mathrm{a}$ \\
\hline $\begin{array}{l}\text { Mastite } \\
\text { subclínica }^{3}\end{array}$ & $7,52 \mathrm{a}$ & $7,57 \mathrm{a}$ & $3,10 \mathrm{a}$ & $3,16 \mathrm{a}$ & $4,42 \mathrm{a}$ & $4,41 \mathrm{a}$ & $12,81 \mathrm{a}$ & $13,77 \mathrm{a}$ \\
\hline $\begin{array}{l}\text { Mastite } \\
\text { clínica }^{4}\end{array}$ & $8,42 \mathrm{a}$ & $7,70 \mathrm{a}$ & $2,89 a$ & $2,84 \mathrm{a}$ & $5,53 \mathrm{a}$ & $4,86 \mathrm{a}$ & $12,77 a$ & $12,90 \mathrm{a}$ \\
\hline
\end{tabular}

As médias seguidas pela mesma letra não diferem significativamente pelo teste $F(p<0,05)$.

${ }^{1}$ Veia jugular, ${ }^{2}$ Veia mamária, ${ }^{3}$ Vacas portadoras de mastite subclínica, ${ }^{4}$ Vacas portadoras de mastite clínica

Os níveis sangüíneos de globulina observados por Lopes et al. (1996) foram de 3,0 a 3,48 g/dL. Kaneko et al. (1997) determinaram que estes níveis variam de 3,6 a $4,5 \mathrm{~g} / \mathrm{dL}$. Segundo Whitaker (2000), níveis menores do que $5,0 \mathrm{~g} / \mathrm{dL}$ são considerados normais. A média observada no presente trabalho foi de $3,77 \mathrm{~g} / \mathrm{dL}$, sendo observado um aumento de $17,24 \% \mathrm{e}$ $37,66 \%$ nos animais que apresentaram mastite subclínica e clínica, respectivamente.

Tanto Kaneko et al. (1997) quanto Lopes et al. (1996) determinaram que os valores considerados normais de leucometria global variam de 4,00 a $12,00 \times 10^{3} / \mu \mathrm{L}$. O valor médio observado nas vacas clinicamente sadias foi de 11,69 $\times 10^{3} / \mu \mathrm{L}$. Foi observado um aumento de $13,67 \%$ e $9,75 \%$ nas vacas que apresentaram mastite subclínica e clínica, respectivamente.

$\mathrm{Na}$ determinação dos níveis de proteínas totais e globulinas houve diferença significativa entre os três grupos. Os níveis de proteínas totais e globulinas foram mais elevados nas vacas portadoras de mastite clínica $(8,06 \mathrm{~g} / \mathrm{dL} ; 5,19 \mathrm{~g} / \mathrm{dL})$, sendo seguido das com mastite subclínica (7,14 g/dL; 4,41

\section{Conclusão}

Não houve influência do local de colheita (veia jugular $x$ veia mamária) sobre os níveis sangüíneos de proteínas totais, globulinas, albumina e leucócitos, mas houve diferença significativa destes parâmetros hematológicos entre os diferentes grupos de vacas. $\mathrm{g} / \mathrm{dL})$ e das clinicamente sadias $(6,63 \mathrm{~g} / \mathrm{dL}$; $3,77 \mathrm{~g} / \mathrm{dL})$, respectivamente. O mesmo não foi observado com os níveis de albumina, onde as portadoras de mastite subclínica demonstraram níveis mais elevados $(3,13 \mathrm{~g} / \mathrm{dL})$, não havendo diferença significativa entre as vacas com mastite clínica $(2,86 \mathrm{~g} / \mathrm{dL})$ e as clinicamente sadias $(2,86 \mathrm{~g} / \mathrm{dL})$.

$\mathrm{Na}$ determinação da leucometria global também houve diferença significativa entre os grupos. As concentrações de leucócitos foram mais elevadas nas vacas portadoras de mastite subclínica $\left(13,29 \times 10^{3} / \mu \mathrm{L}\right)$, sendo seguida das portadoras de mastite clínica $(12,83$ $\left.\mathrm{x} 10^{3} / \mu \mathrm{L}\right)$ e posteriormente pelas sadias $(11,69$ $\left.\mathrm{x} 10^{3} / \mu \mathrm{L}\right)$ (Tabela 2).

O aumento da leucometria global, proteínas totais e globulinas nos grupos com mastite clínica e subclínica caracterizam a presença de infecção bacteriana (Doxey, 1971; Carlson, 1996).

Tabela 2: Comparação dos valores de leucometria global, proteínas totais, albumina e globulinas obtidos por meio de colheita de sangue de 45 vacas leiteiras na região Norte do Estado do Rio de Janeiro

\begin{tabular}{lcccc}
\hline & $\begin{array}{c}\text { Leucometria } \\
\text { Global } \\
\left(\times 10^{3} / \mu \mathrm{L}\right)\end{array}$ & $\begin{array}{c}\text { Proteínas } \\
\text { Totais } \\
(\mathrm{g} / \mathrm{dL})\end{array}$ & $\begin{array}{c}\text { Albumina } \\
(\mathrm{g} / \mathrm{dL})\end{array}$ & $\begin{array}{c}\text { Globulinas } \\
(\mathrm{g} / \mathrm{dL})\end{array}$ \\
\hline $\begin{array}{l}\text { Vacas sadias } \\
\text { (15 animais) }\end{array}$ & $11,69 \mathrm{~b}$ & $6,57 \mathrm{c}$ & $2,86 \mathrm{~b}$ & $3,77 \mathrm{c}$ \\
$\begin{array}{l}\text { M. Subclínica } \\
\begin{array}{l}\text { (15 animais) } \\
\text { M. Clínica }\end{array}\end{array}$ & $13,29 \mathrm{a}$ & $7,54 \mathrm{~b}$ & $3,13 \mathrm{a}$ & $4,42 \mathrm{~b}$ \\
$\begin{array}{l}\text { (15 animais) } \\
\text { (15 }\end{array}$ & $12,83 \mathrm{ab}$ & $8,06 \mathrm{a}$ & $2,87 \mathrm{~b}$ & $5,19 \mathrm{a}$ \\
\hline
\end{tabular}

As médias seguidas pela mesma letra não diferem significativamente pelo teste de Tukey $(p<0,05)$.

1 Vacas portadoras de mastite subclínica

${ }^{2}$ Vacas portadoras de mastite clínica

\section{Agradecimentos}

Aos Drs. Lério Gama Sales, Ricardo Enrique Bressan Smith e Marcos Antônio Lima Bragança, pelo inestimável auxílio durante a confecção do trabalho.

\section{Referências}

BLOWEY, R. W. Metabolic profiles. In: ANDREWS, A. H. Bovine Medicine. London: Blackwell Scientific Publications. p. 601-606, p. 922, 1992.

BORGES, J. R. J.; GRANDY, M. C.; SIQUEIRA, A. J. S. Comparação dos níveis de cálcio, fósforo inorgânico, glicose, proteínas totais, albumina no sangue coletado nas veias jugular, mamaria e coccígea em vacas leiteiras. Revista Brasileira de Ciência Veterinária, v. 4, n. 2, p. 63-66, 1997.
O presente trabalho caracteriza que não há restrição ao uso de sangue colhido da veia mamária para dosagem dos parâmetros supracitados, mesmo que a vaca seja portadora de mastite.
CARLSON, G. P Clinical Chemistry Tests. In: SMITH, B. Large animal internal medicine 2. ed., St Louis: Mosby, p. 441-469, p. 2040, 1996. COSTA, E. O. da. Importância da mastite na produção leiteira do país. Revista Educação Continuada CRMV-SP, v. 1, Fascículo 1, p. 3-9, 1998.

CRUZ, C. D. Aplicativo computacional em genética e estatística. Programa GENES (versão Windows), Editora UFV, Viçosa, MG, p. 648, 2001. 
DOXEY, D. L. Veterinary Clinical Pathology. London: Ballière Tindall, p. 356, 1971.

DU PREEZ, J. H.; GIESECKE, W. H. Mastitis. In: COETZER, J. A. W.; THOMSON, G. R. Infectious diseases of liverstock, Oxford University Press, v. 2, Chap. 190, p.1564, 1994.

KELLY, W. R. Diagnóstico clínico veterinário. 2. ed, Barcelona: CECSA, p. 444, 1976.

KANEKO, J. J.; HARVEY, J. W., BRUSS, M. L. Clinical Biochemistry of Domestic Animals. 5. ed., New York, Academic Press, p. 148-149, 1997.

LOPES, S. T. A.; CUNHA, C. M. S.; BIONDO, A. W.; FAN, L. C. Patologia Clínica Veterinária. Santa Maria, RS: Universidade Federal de Santa Maria. p.162-163, 1996.

MACKELAR, J. C. Collection of blood samples and smears for diagnosis. Veterinary Record. v. 86, p. 302-306, 1970.
MAREK, J.; MÒKSY, J. Tratado de diagnóstico clínico de las enfermidades internas de los animales domésticos. 3. ed., Barcelona: Labor, p. 675, 1965.

MEDWAY, W.; PRIER, J.; WILKINSON, J. Patologia clínica veterinária. México: UTEHA, p. 523,1973.

PARKER, B. N.; BLOWEY, R. W. A. Comparison of blood from the jugular vein and coccygeal artery and vein of cows. Veterinary Record, v. 95, p. 14-18, 1974.

PAYNE, J. M.; PAYNE, S. The metabolic profile test. Oxfor: Oxford University Press, p. 179, 1987.

RADOSTITS, O. M.; BLOOD, D. C.; GAY, C. C. Veterinary Medicine, 8. ed., London, Bailliere-Tindall, p. 173, 1994.

WHITAKER, D. A. Use and interpretation of metabolic profiles. In: ANDREWS, A. H. The health of dairy cattle. Blackwell Science, cap. 4, p. $89-107,2000$. 